\title{
Discordantly Elevated Erythrocyte Sedimentation Rate (ESR) and Depressed C-Reactive Protein (CRP) Values in Early Diagnosis of Pulmonary Tuberculosis Patients in Maiduguri, Nigeria
}

\author{
Zaccheaus Awortu Jeremiah $^{1 *}$, Iruoma Leonard ${ }^{2}$, Anthony C. Ezinma ${ }^{2}$ \\ ${ }^{1}$ Haematology and Blood Transfusion Science Unit, Department of Medical Laboratory Science, College of Health Sciences, Niger \\ Delta University, Wilberforce Island, Nigeria; ${ }^{2}$ Department of Medical Laboratory Science, University of Maiduguri, Maiduguri, \\ Nigeria. \\ Email: "zacjerry@yahoo.com, ${ }^{*}$ za.jeremiah@mail.ndu.edu.ng
}

Received January $2^{\text {nd }}, 2013$; revised February $7^{\text {th }}, 2013$; accepted February $15^{\text {th }}, 2013$

Copyright (C 2013 Zaccheaus Awortu Jeremiah et al. This is an open access article distributed under the Creative Commons Attribution License, which permits unrestricted use, distribution, and reproduction in any medium, provided the original work is properly cited.

\begin{abstract}
Background: ESR and CRP measurements reflect different aspects of systemic inflammation. Generally, they are either elevated or depressed at the same time. This study was aimed at evaluating the clinical ability of these markers in the early diagnosis of pulmonary tuberculosis. Materials and Methods: A total of 50 (male 39, female 21) patients who tested positive to Acid Alcohol Fast Bacilli (AAFB) were studied. ESR and CRP values were estimated using standard procedures. Results: The mean ESR value among the AAFB positive patients was $53.16 \pm 4.92 \mathrm{~mm} / \mathrm{hr}$ while the CRP value was $0.273 \pm 0.035 \mathrm{mg} / \mathrm{L}$. Gender and age were not found to have any influence on the ESR and CRP values. No relationship was found to exist between ESR and CRP $(r=0.17 ; p=0.235)$ and age $(r=0.125 ; p=0.388)$. Conclusion: A moderately elevated ESR and low CRP values exist at the early diagnosis of tuberculosis. There is no correlation between ESR and CRP at the onset of tuberculosis; hence CRP cannot be used as a screening tool for early diagnosis of tuberculosis.
\end{abstract}

Keywords: Erythrocyte Sedimentation Rate; C-Reactive Protein; Pulmonary Tuberculosis

\section{Introduction}

Tuberculosis (TB) is still a major socio-economic and public health problem in the developing countries as several African countries have reported increased annual incidence rate [1]. Tuberculosis also accounts for $2.5 \%$ of the global burden of disease and is the commonest cause of death in young women accounting for more death than all other causes of maternal mortality combined [2].

The erythrocyte sedimentation rate (ESR) and the Creactive protein (CRP) are the two most common laboratory measurements of systemic inflammation in clinical practice. These two tests are often used for the diagnosis and monitoring of a variety of conditions in particular rheumatic disease and in infections [3]. The ESR is a very simple measurement of velocity (in $\mathrm{mm} / \mathrm{hr}$ ) of se-

\footnotetext{
${ }^{*}$ Corresponding author.
}

dimentation of erythrocytes in anticoagulated freshly drawn blood in a standardized vertical tube. Inflammatory cytokines, interleukin-6 (IL-6), tumor necrosis factor $(\mathrm{TNF} \alpha)$ and $1 \mathrm{~L}-1$ stimulate the liver to produce acute phase reactant proteins (fibrinogen, immunoglobulin, haptoglobin, CRP and others). These proteins in particular fibrinogen and immunoglobulin increase the dielectric constant in the blood allowing the erythrocytes to form rouleaux and increasing the velocity of their descent in the tube [4]. The ESR is thus an indirect measure of systemic inflammation which has been criticized as being neither sensitive nor specific but is nonetheless widely used [5].

The CRP on the other hand is a highly conserved pentameric peptide produced in the liver in response to inflammatory cytokines. It was discovered in 1930 in the sera of patients with pneumonia [6] and plays a role in the recognition and elimination of foreign pathogens and 
cellular debris. There has been debate as to the accuracy and sensitivity of the ESR and CRP in monitoring tuberculosis patients [7-10]. This study was therefore aimed at evaluating the clinical utility and correlation between the two parameters.

\section{Materials and Methods}

\section{Study Area and Population}

The study was conducted at the University of Maiduguri Teaching Hospital (UMTH), Maiduguri. UMTH is a tertiary referral hospital with 520 beds and also a centre of excellence in infectious disease and Immunology. It is located at Gwange, Maiduguri and is bounded by Chad and Cameroon republics. The subjects for this study included all patients referred by the attending physicians on clinical grounds to the microbiology laboratory for sputum examination and who tested positive for AcidAlcohol Fast Bacilli (AAFB) between November 2011 and March 2012. A total of 50 patients who tested positive for Acid Alcohol Fast Bacilli were studied. Apparently healthy age and sex matched control subjects were sourced from staff and students of UMTH.

\section{Procedures}

\subsection{Erythrocytes Sedimentation Rate (ESR)}

0.4 Milliliter of sodium citrate anticoagulated was pipette into a small container. 1.6 milliliter of EDTA anticoagulated blood was then added and mixes well. The cap of the container was removed and the sample placed in the ESR stand. The Westergren pipette was inserted and was positioned vertically. Using a safe suction method, the blood was drawn to the zero mark of the Westergren pipette avoiding air bubbles. This was allowed to stand for 1 hour. At exactly 1 hour, the level at which the plasma meets the red cells was read in $\mathrm{mm} / \mathrm{hr}$.

\subsection{Determination of C-Reactive Protein}

The CRP level was assayed using an immunoturbidimetric latex agglutination (Cypress Diagnostics, Belgium). The CRP reagent was a suspension of positive latex particles coated with the ganima globulin fraction of anti human CRP specific serum. When CRP is present in the sample, the resulting turbidity was measured colorimetrically at $430 \mathrm{~mm}$. the CRP in each sample was calculated using a standard CRP solution. The normal CRP value for this assay is $0-0.10 \mathrm{mg} / \mathrm{L}$. CRP Patient $=\mathrm{Ab}-$ sorbance of patient $\times$ conc. of standard $(20 \mathrm{mg} / \mathrm{L})$.

\section{Results}

The mean ESR and CRP values among tuberculosis pa- tients are as shown in Table 1. The mean ESR value was $53.16 \pm 4.92 \mathrm{~mm} / \mathrm{hr}$ while the CRP recorded a mean value of $0.273 \pm 0.035 \mathrm{mg} / \mathrm{L}$. The mean values according to gender, age group, gender and age group are also shown. The analysis of variance of means square values of ESR and CRP did not reveal any influence of these demographic characteristics on the mean values (Table 2). The relationship between ESR, CRP and age of the study participant was studied using the Pearson correlation. No relationship was found to exist between ESR and CRP $(r=0.235)$, and age $(r=0.125, p=0.388)$ (Table 3).

\section{Discussion}

This study investigated the ESR and CRP value in early

Table 1. Demographic characteristics of participants.

\begin{tabular}{cccc}
\hline Characteristics & $\mathrm{N}$ & $\begin{array}{c}\text { ESR (mm/hr) } \\
\text { (Mean } \pm \text { SEM) }\end{array}$ & $\begin{array}{c}\text { CRP (mg/L) } \\
\text { (Mean } \pm \text { SEM) }\end{array}$ \\
\hline Overall & 50 & $53.16 \pm 4.92$ & $0.273 \pm 0.035$ \\
Gender & & & \\
Male & 29 & $52.28 \pm 6.05$ & $0.272 \pm 0.048$ \\
Female & 21 & $54.38 \pm 8.38$ & $0.275 \pm 0.051$ \\
Age group (yrs) & & & \\
$<30$ & 19 & $52.47 \pm 8.48$ & $0.247 \pm 0.059$ \\
$30-45$ & 15 & $44.47 \pm 6.38$ & $0.266 \pm 0.071$ \\
$46+$ & 16 & $62.13 \pm 9.93$ & $0.311 \pm 0.054$ \\
Average age [35.20 \pm 2.12$]$ & & & \\
Gender $\times$ age group & & & \\
Male $<30$ & 9 & $46.78 \pm 11.73$ & $0.203 \pm 0.085$ \\
$30-45$ & 11 & $50.82 \pm 10.61$ & $0.260 \pm 0.077$ \\
$46+$ & 9 & $59.56 \pm 11.73$ & $0.354 \pm 0.085$ \\
Female $<30$ & 10 & $57.60 \pm 11.12$ & $0.286 \pm 0.081$ \\
$30-45$ & 4 & $47.00 \pm 17.59$ & $0.281 \pm 0.128$ \\
$46+$ & 7 & $65.43 \pm 13.30$ & $0.254 \pm 0.097$ \\
\hline
\end{tabular}

No significant difference $(\mathrm{p}>0.05)$ was observed within the different characteristics and their interaction.

Table 2. Mean squares from analysis of variance of ESR and CRP.

\begin{tabular}{cccccc}
\hline & & \multicolumn{2}{c}{ ESR $(\mathbf{m m} / \mathbf{h r})$} & \multicolumn{2}{c}{ CRP $(\mathbf{m g} / \mathbf{L})$} \\
\cline { 3 - 6 } Source & df & $\begin{array}{c}\text { Means } \\
\text { square }\end{array}$ & F-value & $\begin{array}{c}\text { Means } \\
\text { square }\end{array}$ & F-value \\
\hline Sex & 1 & 62.95 & $0.051^{\text {ns }}$ & 0.000024 & $0.000^{\text {ns }}$ \\
Age group & 2 & 1870.13 & $1.511^{\text {ns }}$ & 0.015 & $0.235^{\text {ns }}$ \\
Sex $\times$ age group & 2 & 1176.47 & $0.951^{\text {ns }}$ & 0.036 & $0.556^{\text {ns }}$ \\
Error & 44 & 1297.40 & & 0.065 & \\
Corrected total & 49 & & & & \\
\hline
\end{tabular}

${ }^{\mathrm{ns}}$ Not significant $(\mathrm{p}>0.05)$. 
Table 3. Relationship between ESR, CRP and age among the tuberculosis patients.

\begin{tabular}{cccc}
\hline Parameter & & CRP & Age \\
\hline ESR & $\mathrm{r}$ & $0.171^{\text {ns }}$ & $0.125^{\text {ns }}$ \\
& p-value & 0.235 & 0.388 \\
CRP & $\mathrm{r}$ & & $0.133^{\text {ns }}$ \\
& p-value & & 0.358 \\
\hline
\end{tabular}

diagnosed tuberculosis patients in order to evaluate their clinical utility in managing tuberculosis. The main findings of the study include: 1) A moderately elevated ESR values and a low CRP values; 2) Absence of correlation between ESR and CRP values. This finding were found to be at variance with a recent study in Nigeria [11] where the CRP values were found to be elevated at first diagnosis. However, it is important to note that previous studies that reported elevated CRP values were carried out on chronic tuberculosis patients [12]. A moderately elevated ESR among these tuberculosis patients is in consonance with previous reports where moderately to extremely elevated ESR values were reported [13].

One of the novel findings in this study is the discordance that exists between these two markers in this study. By the time a patient is tested positive for AAFB, a process of inflammation must have been going on for some period of time. The null hypothesis is that both markers are elevated in tuberculosis. This study rejects this null hypothesis. The difference in the response mechanism between ESR and CRP will form the basis of discussion in this paper.

The C-reactive protein methods used in the laboratory are a more direct measure of the inflammatory process because only CRP is measured. ESR on the other hand reflects the concentration of several plasma proteins including fibrinogen, $\alpha$-globulins, $\beta$-globulins, immunoglobulins and albumin [14]. Therefore, any condition (pathological or non-pathological) that affects any of the contributing proteins can alter the ESR. Both CRP and ESR have characteristic pattern of response. CRP begins to rise within 4 - 6 hours of stimulus, peaks at 36 - 50 hours and returns to normal 3 - 7 days following resolution. On the other hand, ESR shows a much slower response, taking up to a week to peak and up to several weeks to return to normal [15]. It is therefore possible that at the time of presentation for diagnosis, CRP has returned to normal values while ESR is yet to peak.

This disproportionate and discordant result between CRP and ESR has been reported of rheumatoid arthritis condition [16]. Wolfe [16], reported in that study, that ESR correlates better than CRP with measures of chronic inflammation such as anaemia, immunoglobulin eleva- tion as well as with rheumatoid factor. He also suggested that ESR may be a better measure of chronic inflammation in RA while CRP more accurately reflects the acute phase response [16]. Although ESR and CRP measurements reflect different aspects of systemic inflammation, generally they are either elevated or depressed at the same time. As CRP is sensitive, it has been frequently used clinically as a marker to evaluate disease condition (early diagnosis or disease activity) $[17,18]$. Studies have shown that in the active stage (tissue injury degree and injury repair time) serum ESR and CRP exhibited changes in patients with tuberculosis [19]. Kartaloglu et al. [20] concluded in their study that ESR and CRP were increased firstly and gradually decreased in different stages before and after treatment, similar to adenosine deaminase changes. Some researchers have regarded ESR and CRP as objective indexes to evaluate tuberculosis treatment [21,22].

We concluded that CRP measurement in the early stage of pulmonary tuberculosis is not necessary. ESR measurement, though not specific seems to be of more value in early diagnosis of tuberculosis than CRP. However, there are some limitations in the present study. The sample size was small and the patients were not followed up to observe the trend in the charges in ESR and CRP values. The subjects were recruited only in one hospital which also affected the number of positive patients in this study.

\section{REFERENCES}

[1] T. Frieden, T. Stering, S. Munsiff, C. Watt and C. Dye, “Tuberculosis," The Lancet, Vol. 362, No. 7, 2003, pp. 887-889.

[2] I. Smith and P. L. Lin, "Rodgers Quantitative Comparison of Active and Latent Tuberculosis in the Cynomolgus Macaque Mode," Infection and Immunity, Vol. 12, No. 77, 2009, pp. 845-855.

[3] K. H. Costenbader, L. B. Chibnik and P. H. Schur, "Discordance between Erythrocyte Sedimentation Rate and c-Reactive Protein Measurement: Clinical Significance,” Clinical and Experimental Rheumatology, Vol. 25, No. 5, 2007, pp. 746-749.

[4] L. Holley, N. Woodland, W. T. Hung, et al., "Influence of Fibrinogen and Hematocrit on Erythrocyte Sedimentation Kinetics,” Biorheology, Vol. 36, 1999, pp. 287-297.

[5] H. C. Sox and M. H. Liang, "The Erythrocyte Sedimentation Rate. Guidelines for Rational Use,” Annals of Internal Medicine, Vol. 104, No. 4, 1986, pp. 515-523. doi:10.7326/0003-4819-104-4-515

[6] W. S. Tillet and T. Francis, "Serological Reactions in Pneumonia with a Non Protein Somatic Fraction of Pneumococcus," Journal of Experimental Medicine, Vol. 52, No. 4, 1930, pp. 561-571. doi:10.1084/jem.52.4.561

[7] M. B. Pepys, J. G. Lanham and F. C. De Beer, "C-Reac- 
tive Protein in SLE,” Chin Rheum Dis, Vol. 8, 1982, pp. 91-103.

[8] C. Gabay, P. Roux-Lombard, P. De Moer-Loose, et al., "Absence of Correlation between Interleukin 6 and CReactive Protein Blood Levels in Systemic Lupus Erythematosus Compared with Rheumatological Arthritis,” Journal of Rheumatology, Vol. 20, 1993, pp. 815-821.

[9] L. M. Vila, G. S. Alarcon, G. J. McGin, et al., "Systemic Lupus Erythematosus Cohort (LUMINA): XXIX. Elevation of Erythrocyte Sedimentation Rate Is Associated with Disease Activity and Damage Accrual," Journal of Rheumatology, Vol. 32, 2005, pp. 2150-2155.

[10] C. N. Suh, H. Y. Chun, Y. M. Ye, et al., "Unresponsiveness of C-Reactive Protein in the Non Infectious Inflammation of Systemic Lupus Erythematosus Is Associated with Interleukin 6,” Clinical Immunology, Vol. 119, No. 3, 2006, pp. 291-296. doi:10.1016/j.clim.2005.11.006

[11] D. A. Ojo, S. J. Jacob and C. I. Ayolabi, "C-Reactive Protein in Tuberculosis and Human Immunodeficiency Virus Infections in Abeokuta, Nigeria,” Bayero Journal of Pure and Applied Sciences, Vol. 4, No. 2, 2011, pp. 91-96.

[12] J. Van der Broek, G. Arpacia and G. Gilberto, "Impact of Human Immunodeficiency Virus Infection on the Outcome of Treatment and Survival of Tuberculosis Patients in Mivariza, Tanzania,” International Journal of Tuberculosis, Vol. 2, No. 7, 2008, pp. 547-552.

[13] E. J. Kanfer and B. A. Nicol, "Haemoglobin Concentration and Erythrocyte Sedimentation Rate in Primary Case Patients," Journal of the Royal Society of Medicine, Vol. 120, No. 1, 1997, pp. 54-62.

[14] T. Husain and D. Kim, "C-Reactive Protein and Erythrocyte Sedimentation Rate in Orthopaedics," The University of Pennysylvannia Orthopaedic Journal, Vol. 15, 2002, pp. 13-16.

[15] S. G. Deodhase, "C-Reactive Protein,” Clinical Applications. http://www.embeediagnostics.com/features/crp.htm

[16] F. Wolfe, "Comparative Usefulness of C-Reactive Protein and Erythrocyte Sedimentation Rate in Patients with Rheumatoid Arthritis,” Journal of Rheumatology, Vol. 24, 1997, pp. 1477-1485.

[17] L. Xu and Y. Y. Gu, “The Significance of C-Reactive Protein I Systemic Lupus Erthematosils Activity and Infection,” Zhongua Fengshibing Xue Zahzhi, Vol. 4, No. 6, 2000, pp. 288-389.

[18] D. L. Jaye and K. B. Waites, "Clinical Applications of C-Reactive Protein in Pediatrics," Pediatric Infectious Disease Journal, Vol. 16, No. 8, 1997, pp. 735-747. doi:10.1097/00006454-199708000-00003

[19] X. N. Tian, "Clinic Diversity Analysis of ESR after AntiTuberculosis Treatment in Bone and Joint Tuberculosis," Zhongguo Jiaxing Waike Zazhi, Vol. 10, No. 9, 2005, pp. 1512-1513.

[20] Z. Kartaloglu, O. Okutan, E. Bozkanat, et al., "The Course of Adenosine Deaminase Levels in Patients with Pulmonary Tuberculosis," Medical Science Monitor, Vol. 12, No. 11, 2006, pp. 476-480.

[21] W. M. Jin and H. Y. Zhu, "The Clinical Value of CRP in Diagnosis Tuberculosis,” Linchuang Feike Zazhi, Vol. 13, No. 3, 2008, p. 306.

[22] D. Wilson, J. Nachega, C. Morroni, et al., "Diagnosing Smear Negative Tuberculosis Using Case Definitions and Treatment Response in HIV Infected Adults," International Journal of Tuberculosis and Lung Disease, Vol. 10, No. 1, 2006, pp. 31-38. 